\title{
Student perceptions of electronic health record use in simulation
}

\author{
Debra A. Jansen \\ College of Nursing and Health Sciences, University of Wisconsin-Eau Claire, Eau Claire, Wisconsin, USA. \\ Correspondence: Debra A. Jansen. Address: College of Nursing and Health Sciences, University of Wisconsin-Eau Claire, \\ Eau Claire, Wisconsin, USA. Email: jansenda@uwec.edu
}

Received: May 30, 2014

Accepted: July 11, 2014

Online Published: July 27, 2014

DOI : 10.5430/jnep.v4n9p163

URL: http://dx.doi.org/10.5430/jnep.v4n9p163

\section{Abstract}

Background/Objectives: Use of an electronic health record (EHR) system is a necessary part of the educational experience of nursing students. The purposes of this evaluation project were to ascertain from baccalaureate nursing students their perceptions of the importance of an EHR system and simulation to their education and their evaluations of one particular simulation/EHR system (S/EHR).

Methods: Sixteen baccalaureate nursing students completed a survey, following use of the S/EHR in simulated clinical practice.

Results: Despite technical challenges, the majority of students agreed the S/EHR was realistic, easy to work with, and increased their confidence and ability to safely provide patient care and administer medications. The majority felt it was important for the nursing program to use some type of EHR and desired more simulations.

Conclusions: The S/EHR contributed to the realism of the simulation experiences. Considerations are provided for nursing programs needing to obtain and implement an EHR system for educational purposes.

\section{Key words}

Electronic health record, Electronic medical record, Nursing education, Human patient simulation

\section{I ntroduction}

Experience with an Electronic Health Record (EHR) is now a necessary part of the education of undergraduate and graduate nursing students ${ }^{[1]}$. The U.S. had been slow to use EHRs in health care environments in comparison to many other countries, including Denmark, Sweden, and New Zealand ${ }^{[2]}$. The 2009 American Recovery and Reinvestment Act, however, has rapidly increased EHR utilization by health care professionals and medical facilities. The Act provides for Medicare and Medicaid government incentive payments to hospitals and health care providers who meaningfully use an EHR system, i.e., meet thresholds for quality objectives and measures ${ }^{[3,4]}$.

The need to use some type of EHR system in nursing programs is consistent with recommendations from professional organizations, including the American Association of Colleges of Nursing ${ }^{[5-7]}$, the National League for Nursing ${ }^{[8]}$, and the International Medical Informatics Association ${ }^{[1]}$. In the Institute of Medicine (IOM) report, the Future of Nursing: Leading Change, Advancing Health ${ }^{[9]}$, the IOM indicated, "In the future virtually every facet of nursing practice in each 
setting where it is rendered will have a significant digital dimension around a core electronic health record” (p. 384). The group recommended the use of innovative strategies, particularly simulation, to transform nursing education to ensure that nurses achieve essential competencies. They also noted that simulation could be used to provide learning opportunities in areas where suitable clinical placement sites are not available. To replicate the realities of a clinical situation, such simulations need to include the use of an EHR. Besides enabling students to learn how to access, analyze, and record patient information, having an EHR allows them to practice maintaining nurse-patient relationships and communication in the presence of technology. For instance, simulations utilizing EHRs permit students to practice establishing and maintaining verbal and eye contact with patients and families while charting on computer or mobile devices ${ }^{[10,11]}$.

Through a university system curricular redesign grant, five state system nursing programs received funds to collectively explore and purchase an EHR system for a trial period. A commercially available simulation/EHR system (S/EHR) was selected by the schools. The S/EHR is an internet-based program consisting of written simulation scenarios for use with mannequins and an EHR component that provides students experiences in reviewing, analyzing, and documenting patient health information, assessments, and interventions. The purposes of this evaluation project were to ascertain from undergraduate nursing students at one of the five universities 1) their perceptions of the importance of an EHR system and simulation to their education and 2) their evaluations of the S/EHR. The results were to be used by the nursing program in decision making pertaining to purchasing the system following the trial period. Each of the five nursing programs was to make its own determination regarding purchasing or otherwise obtaining an EHR system for future use at its location. Thus, data for this particular evaluation project were collected and reported from only the one university. Additionally, besides revealing possible challenges with the use of the system, potential findings also could provide evidence to encourage faculty at the university to utilize an EHR along with simulation in their courses, as resistance to simulation and EHRs was still present among some educators.

\subsection{Selection of an EHR to trial}

In selecting an EHR to trial, faculty and administrators quickly realized the various health care agencies used for student clinical placements utilized different EHR systems, even within the same cities. Thus, it would not be possible to find a system common to all the communities. Furthermore, no clinical-academic partnerships existed yet for collaboration on an EHR for student use and practice. In the end, the agreement was to purchase one system to be used by all of the schools during the grant period. Prior to the purchase of a system to trial, the five nursing programs reviewed seven different EHR options. Considerations included the various goals of the nursing programs (e.g., to use with simulations); fees (setup, annual site license, and per student); the availability of patient cases to pre-populate the system; the completeness of patient data; the ability to document notes and medications; the ease of viewing patient data, including lab results and orders; ease of accessing/logging into the system; ease of understanding of the computer screen displays; currency with practice; ease of implementing the system by faculty; the ability of faculty to modify patient data (if cases pre-populated the system); and degree of support help needed to setup and maintain the system. Concerns found with a number of the options included high annual site license and individual student fees. The more complex systems also necessitated additional dedicated information technology (IT) staff to manage them.

After reviewing demonstrations of a beta version of the S/EHR, the decision was made to purchase site licenses and student access codes for it for an 18 month trial period. No costs were passed on to students during the trial period. The faculty felt the S/EHR was less cost prohibitive to purchase and maintain than other systems reviewed. Additionally, many of the schools already were using the textbooks associated with the S/EHR (student access codes could be packaged and sold with the textbooks, at a reduced cost to students). The system also appeared to be easy enough for faculty to implement, without the need to hire an IT support person; and the computer screen displays of patient data seemed readily interpretable and intuitive regarding how and where to document. Moreover, faculty were appreciative of the simulation scenarios and patients that pre-populated the EHR and were informed that the ability to "author" or modify patient scenarios or data would be available in the near future. 


\subsection{Theoretical framework}

The Nursing Education Simulation Framework ${ }^{[12]}$ was used to guide the implementation of the S/EHR and this evaluation project. Central elements of the Framework include teacher and student factors, educational practices, simulation design characteristics, and expected student outcomes. The goals of implementing the S/EHR included influencing the educational practices and simulation design characteristics of the simulation experiences conducted with our undergraduate nursing students, thereby promoting enhanced expected student outcomes. Educational practices are means of promoting learning, including active involvement in the simulation experiences. With the use of an EHR, students engage in the hands-on activities of electronically accessing and critically evaluating patient data and documenting actions. Simulation design characteristics include the degree of simulation realism or fidelity, the level of complexity of the simulation experience, and opportunities for debriefing. Utilizing an EHR enhances the realism and depth of the simulation experience, thus increasing the ability of the students to practice safely and with more confidence in the clinical setting (the expected student outcomes).

\subsection{Literature review}

A number of authors have written about their experiences with incorporating informatics content, including the use of EHRs, into nursing pre-licensure curricula. EHRs have been used in conjunction with narrative case studies in which students were asked to document relevant case information ${ }^{[13,14]}$, or incorporated into medium and high fidelity simulations ${ }^{[15-19]}$. Meyer et al. ${ }^{[17]}$ required junior nursing students to access a simulated EHR for patient information prior to four simulations, comparable to how they would prepare for clinical experiences, and to document cares as part of the simulation sessions. The authors found these students adapted more quickly to a real pediatric clinical environment and were rated statistically significantly higher on a clinical performance measure than students without the simulation/EHR exposure prior to the clinical rotation.

In a needs assessment survey by Lucas ${ }^{[10]}$ of faculty and students at one university, faculty commented that students had insufficient opportunity to practice charting prior to their clinical experiences. The majority of students complained that a barrier to their clinical education was electronic documentation because they were overly occupied with learning the computer system. After the university partnered with an acute care facility to access the facility's EHR training system, students were able to participate in realistic simulations at the school laboratory that included the use of the EHR, prior to engaging in clinical experiences at the facility. In a subsequent questionnaire, the students described feeling more confident with charting and with the EHR and appreciated being able to practice on the EHR from their homes.

The literature related to nursing student and faculty evaluations and perceptions of particular EHR systems is rather limited. Gloe ${ }^{[20]}$ provided a detailed plan for studying, reviewing, and selecting an EHR for academic purposes. Major steps included choosing a review committee; developing a plan; listing potential vendors; scheduling product demonstrations; sending product comparison questions to three or four final vendors of interest; and picking a vendor. Gloe emphasized that each nursing program needs to individually determine which features are most important to its programming.

Nickitas et al. ${ }^{[21]}$ noted the challenges with an EHR system faculty encountered when they formed a clinical-academic partnership with a local U.S. Veterans Administration system to use its EHR to teach documentation skills in the school laboratory. These included log-in access issues, wireless connection difficulties, and lack of autonomy over the content and system.

Bowers et al. ${ }^{[22]}$ described the creation of a Student Nurse Portal (SNP) consisting of a series of online student clinical preparatory courses pertaining to the purpose and use of EHRs, along with a generic EHR that enabled data entry practice for patient scenarios. Nursing students completed these courses prior to starting clinical rotations at the area agencies. Student evaluations of the SNP were positive, with $66 \%$ indicating that with some preliminary coaching by their instructors, they were well prepared to use the EHR at their clinical setting. 
Hanberg and Madden ${ }^{[23]}$ described how students used an EHR to retrieve data prior to and during human patient simulator (HPS) simulations, document interventions and outcomes, and engage in debriefing and synthesis. Despite anecdotal complaints from faculty and students that the systems were too complicated and onerous, the students "felt they had gained competencies both in using information technology and in managing data electronically" (p. 136). Further student feedback indicated the students desired "consistency and additional guidance from faculty members" (p. 136).

In summary, in nursing education, EHRs have been used successfully in conjunction with narrative case studies as well as with simulations to increase confidence and competence in the clinical environment. However, findings from faculty and students related to their evaluations and perceptions of particular EHR systems tended to be more limited and anecdotal.

\section{Methodology}

\subsection{Design}

This evaluation project utilized a single group descriptive design. A written survey was developed to ascertain from undergraduate nursing students 1) their perceptions of the importance of an EHR system and simulation to their education and 2) their evaluations of the S/EHR. Feedback from students may elucidate challenges to address to ensure successful EHR and simulation implementation as well as inform decisions related to purchasing and acquiring particular EHR systems. Findings also may provide further support for utilizing EHRs with simulation in more nursing curricula.

\subsection{Measure}

A survey was created for this evaluation project. The survey originally consisted of 12 closed-ended items that enabled students to rate their perceptions of the realism, ease of use, and ability of the S/EHR to increase clinical skills and confidence. Likert-scale ratings ranged from 1 (strongly disagree) to 6 (strongly agree). The tool and S/EHR were initially piloted with two senior undergraduate nursing students. Two of the 12 closed-ended items were later removed due to item redundancy and lack of clarity, thereby reducing the survey to 10 items (see Table 1). The survey also included 10 open-ended questions pertaining to what was helpful and not helpful about the EHR component of the S/EHR and the overall S/EHR, relevance to practice, areas for improvement, and recommendations for future use. The survey items and questions were adapted from previously published and used EHR and simulation related surveys (e.g., by Bearnson \& Wiker ${ }^{[24]}$ ) and included additional items of interest to the nursing faculty and administrators needing to decide whether to purchase the S/EHR for future use. Items relevant to both EHR systems and simulation were included as the intent of the nursing program was to utilize an EHR system in conjunction with simulation. The survey was reviewed by a faculty member with clinical simulation expertise and by one with research and evaluation acumen as a means of supporting the instrument's face validity and to provide feedback regarding item clarity, ease of use, and readability.

Table 1. Survey items percentages and means

\begin{tabular}{lll}
\hline Item & \% Agreed* & Mean (SD) \\
\hline The EHR system was realistic. & $100 \%$ & $4.8(.4)$ \\
The S/EHR provided a realistic clinical experience. & $88 \%$ & $4.4(.7)$ \\
I would like to have more mannequin-based simulations in courses. & $88 \%$ & $4.6(1.1)$ \\
It is important for the nursing program to use some type of EHR system. & $81 \%$ & $4.9(1.1)$ \\
A student user fee of up to \$50.00 per student (good for 3 years) is a reasonable expectation for & $63 \%$ & $3.8(1.4)$ \\
access to an EHR system. & $88 \%$ & $4.3(.7)$ \\
The S/EHR was easy to work with. & $69 \%$ & $4.0(1.0)$ \\
The S/EHR increased my ability to provide safe patient care. & $94 \%$ & $4.4(1.2)$ \\
The S/EHR increased my ability to administer medications safely. & $75 \%$ & $4.4(1.0)$ \\
The S/EHR increased my confidence in my medication administration skills. & $63 \%$ & $4.1(1.1)$ \\
The S/EHR increased my overall confidence in the clinical setting. & \\
\hline
\end{tabular}

* = percent of student who slightly (4) to strongly agreed (6) with an item. $N=16$ students in the accelerated bachelor of science in nursing (BSN) program. S/EHR = Simulation/Electronic Health Record system. EHR = Electronic Health Record. 


\subsection{Sample}

The convenience sample consisted of all $(N=$ sixteen) undergraduate bachelor of science in nursing students enrolled at the University in a one-year accelerated program for second degree students (students who had previously earned a baccalaureate degree in another field). Thirty-eight percent had previously worked with an EHR system in a clinical setting.

\subsection{Procedure}

The S/EHR was introduced to the 16 students in the accelerated nursing program as part of an initial course in which the students learned documentation in the skills laboratory and classroom, prior to taking part in hospital clinical experiences. In the course, they participated in five acute care S/EHR scenarios pertaining to the care of adult patients (e.g., the management of postoperative fluid volume following abdominal surgery, the recognition and treatment of pulmonary embolism after knee arthroplasty, and tracheostomy management for a patient with a subarachnoid hemorrhage), plus utilized the system for four more scenarios for medication administration practice and competency check-offs. Students were assigned simulated patients and expected to review patient data in the S/EHR and develop initial care plans prior to the simulations. After the simulations the care plans were completed. The survey was administered in paper form in the classroom following course completion (and participation in hospital-based clinical experiences) and after obtaining informed consent, as approved by the Institutional Review Board.

\subsection{Data analysis}

Means and standard deviations were calculated for each of the 10 Likert-scale survey items for the 16 students in the accelerated program. The percentage of students who agreed with each item was calculated as the total percentage of students who rated the item with a 4 (slightly agree), 5 (agree), or 6 (strongly agree). A review of the responses to the 10 open ended survey questions revealed considerable redundancy and overlap among the answers. Therefore, the investigator pooled all of the responses to the ten questions and conducted a single content analysis, using an empiric-analytic inductive technique to categorize the data ${ }^{[25]}$. The content analysis technique included 1) creating a computer printout listing all participant responses for a given question, 2) segmenting each of the responses into individual thematic units, 3) reviewing all responses, 4) creating and naming categories or clusters of themes based on similarities among the data, and 5) sorting the thematic units into the categories.

\section{Results}

\subsection{Evaluation findings - Likert-scale survey items}

Table 1 lists the Likert-scale survey items and means, along with the total percentage of students who slightly (4) to strongly agreed (6) with the item. Means for the individual ten items ranged from 3.8 to 4.9. Because of this project's exploratory nature, means for the individual item, "The Electronic Health Record (EHR) system was realistic," were compared for those students with prior experience with an EHR and those who had not previously used an EHR in a clinical setting. Those students with prior experience $(n=6)$ more strongly and significantly agreed the EHR was realistic $(M=5.0, S D=.00)$ than did those without experience $(n=10, M=4.6, S D=.52) ; t(14)=2.45, p=.04)$.

\subsection{Content analysis categories}

In conducting the content analysis of the data from the open-ended questions, the investigator identified eight categories of themes (see Table 2). The categories are described in order of frequency, from those with the greatest number of participant responses to those with the fewest. Support for the trustworthiness of the analysis is provided through the inclusion of direct quotes from participants in the following category descriptions ${ }^{[26]}$. 
Table 2. Frequencies of participant responses for the eight content analysis categories

\begin{tabular}{ll}
\hline Category & Number of responses* \\
\hline Not used to full or intended potential & 27 \\
Provided helpful practice opportunities and preparation for clinical & 21 \\
Similar to EHRs found in clinical agencies & 20 \\
Provided extensive and in-depth patient data & 19 \\
Easy to use & 15 \\
Promoted realism of simulations & 9 \\
Helpful but not needed relative to costs & 8 \\
Online accessibility and log-in issues & 7 \\
\hline
\end{tabular}

$*=$ Frequencies reflect multiple responses from some participants. $\mathrm{N}=16$ students in the accelerated bachelor of science in nursing (BSN) program.

\subsubsection{Not used to full or intended potential}

This first category was the most popular, with 27 student responses and referred to the way the S/EHR was used in the clinical laboratory. Faculty and students often felt it was too complicated and laborious to have every student fully log in to the S/EHR using their own usernames and passwords whenever they needed to review patient information or document actions such as administering medications. Consequently, the faculty frequently used a "demo" mode or logged into a pretend student's account; in these cases, students were asked not to chart, since any saved response would be visible to subsequent students if everyone used the same opened account. These compromises prompted comments such as, "We were told not to save our documentation to the EHR after our in-class simulations" because it would "alter the records." Another student added, "We couldn't actually chart/document our experiences. There would be saved info from other students when we would use it.”

\subsubsection{Provided helpful practice opportunities and preparation for clinical}

This category included evidence of student appreciation for being able to practice using an EHR, as opposed to utilizing paper documentation. To that end, students noted that "most hospitals have electronic med records so it is very useful for us to practice with an EHR before clinical"; and the system "provided an opportunity to practice documentation and assessing information on an EHR like we are expected to do in real life, now in clinical and upon graduation.” Another student was in favor of recommending the system, as "I was able to pick up on the EHR in clinical faster." Similarly, others believed "It does help one adjust to using the computer to access a patient's info"; and it "allowed us to practice finding info and determining what meds to give when."

\subsubsection{Similar to EHRs found in clinical agencies}

Students' perceptions that the EHR was "very similar to what was used in the clinical setting" and was "very realistic" were reflected in this category. They felt, "it provides similar data, and in a similar fashion to what was used in clinical."

\subsubsection{Provided extensive and in-depth patient data}

This category pertained to the "completeness of the scenario information" and the belief the EHR "provided a lot of useful information that aided ... in preparing for class and scenarios." Nineteen responses were sorted into this category and included, for example, the system "provided info in-depth" with "excellent detail”; "extensive patient detail available in clinical format”; and "patients were given a face and a full history."

\subsubsection{Easy to use}

The Easy to Use category included positive statements such as, "the EHR was fairly easy to navigate through"; "was easy to use"; and was "organized." Additionally, "the info was clearly labeled and easy to find" and the EHR was "much more straight-forward" and was "way better/user friendly" than the EHR of a local clinical agency. 


\subsubsection{Promoted realism of simulations}

Nine responses were sorted into this category and included the students' perceptions that the "EHR system made the simulation seem more like a clinical experience" and "it felt like we worked with real patients." Similarly, one student added that the EHR "helps to feel like the scenario with SimMan is more involved and worthwhile." Another believed the EHR "helps foster the same kind of environment that student nurses work in for clinicals" as they practice assessing and documenting information on simulated patients under their care.

\subsubsection{Helpful but not needed relative to costs}

The Helpful but Not Needed Relative to Costs category included eight responses. One student who despite strongly agreeing with the Likert-scale item, "It is important for the nursing program to use some type of EHR," wrote that "it is a good learning experience, though I am not sure it is worth" the cost. Students indicated it was "helpful," but believed a facility's EHR "wasn't very complicated to learn so it could just be learned in the clinical setting rather than in class," especially since "for the amount of time we used it in class, it would be almost as beneficial to just learn it at clinical". As another student noted, “every organization’s EHR is different so one has to adapt when in a different setting”.

\subsubsection{Online accessibility and log-in issues}

The final category included seven responses from students describing their concerns. These included, for instance, "the sign-in process is somewhat laborious" and students "had to go through many screens after logging in to find the EHR." A couple students related not being able to access the website on some computers, with one student preferring "hard copy that works without internet."

\section{Discussion}

A review of the individual survey item means revealed that despite technical challenges, the majority of students agreed the S/EHR was realistic, easy to work with, and increased their confidence and ability to safely provide patient care and administer medications. These survey item findings were consistent with the content analysis results, and particularly coincided with the categories of "Provided Helpful Practice Opportunities and Preparation for Clinical," "Similar to EHRs Found in Clinical Agencies," "Easy to Use," and "Promoted Realism of Simulations.” The EHR component contributed to the Nursing Education Simulation Framework's educational practices through the hands-on activities, as well as the degree of simulation fidelity or realism, an important simulation design characteristic of the Framework.

Students found value in the S/EHR but not surprisingly, some felt reluctant to pay for access. Eight responses were coded into the content analysis category, "Helpful but Not Needed Relative to Costs." Those respondents tended to believe EHR systems were simple enough to be learned on-site in clinical, if it meant saving them additional expenses. Their responses also suggested faculty were not sufficiently using the S/EHR in classes to make the system seem worth the cost. However, more than half (63\%) of the students agreed with the item, "A student user fee of up to $\$ 50.00$ per student (good for 3 years) is a reasonable expectation for access to an EHR system.” This item did not reflect the actual S/EHR student access code costs, but was intended to gauge student reactions to potentially charging an access fee in the future.

Technical challenges interfered with the full use of the system, as reflected by the most popular content analysis category, "Not Used to Full or Intended Potential," and the category, "Online Accessibility and Log-In Issues.” As previously described, faculty frequently advised students not to document or save their charting, as faculty often bypassed having students fully log in to the S/EHR to save time. Both faculty and students found the log-in process to be laborious, involving "too many clicks." Although faculty attempted to save time, they inadvertently interfered with the realism of the simulation experiences. In clinical practice, nurses contend with log-in issues that students need to be prepared to manage. When instructors bypass log-in procedures, they could be unintentionally endorsing workarounds that compromise patient confidentiality and safety and nurse integrity. 
The challenges described by the students were similar to those previously noted by Nickitas et al. ${ }^{[21]}$ for the Veterans Administration EHR, e.g., requiring too much time and steps to log on and wireless access issues. The concerns also were like the anecdotal faculty complaints related by Hanberg and Madden ${ }^{[23]}$, i.e., both the EHR and patient simulation systems they used were "complicated, tedious, time-consuming, and demanding" and students indicated they were unable to "master" the EHR due to its inconsistent usage (p. 135). However, in keeping with the students in the Hanberg and Madden study who described "enjoying the HPS experiences and requested more” (p. 135), 88\% of the students in the present evaluation project indicated they would like more simulations in their courses.

A particularly relevant finding was that the majority (81\%) of the students who participated in this evaluation project felt it was important for the nursing program to use some type of EHR system. It was not necessary for the classroom EHR system to match those seen in the clinical agencies. A few students acknowledged that health care agencies tend to have different EHRs and individuals have to "adapt when in a different setting”.

After reviewing the student responses and their own experiences with the S/EHR, faculty at the University supported continuing to utilize the system following the grant trial period. The nursing program currently pays for the annual site license and the students purchase access codes, as part of a textbook package. Now that students purchase entree to the system, faculty feel an extra obligation to make certain the S/EHR is utilized throughout their program. With the majority of students indicating a desire for more mannequin-based simulations and the use of some type of EHR, simulation and EHR faculty champions were able to use these data to encourage more of the faculty to incorporate the use of EHRs and simulation into their courses.

Results of this evaluation project also informed faculty regarding areas of concern related to the S/EHR that could be addressed. For instance, a major concern by the students was that faculty were not using the system as intended, e.g., not consistently having the students log in or actually chart and save their documentation. More orientation to the system and growing experience and comfort by the faculty can ease some of the concerns. Continued discussions with the manufacturer as issues arise also can inform future system upgrades.

By utilizing EHRs from the very beginning of a student's entry into a nursing program, students are not forced to transition from paper to electronic systems. Instead, utilizing EHRs becomes automatic to them, enabling them to focus on the patient situation, rather than the technology. If an EHR system is used from the start, fewer negative experiences may be noted, like those reported by Donahue and Thiede ${ }^{[27]}$, who found resistance, anxiety, and anger by the first student cohort using an EHR in a nursing curriculum. They noted students had a difficult time adapting from paper charting to an electronic system, the same pattern seen among staff in healthcare organizations transitioning to EHRs ${ }^{[27]}$.

A goal in integrating an EHR system into nursing education needs to include promoting a student's ability to critically think and engage the nursing process, while utilizing an EHR. The focus is less on a particular EHR system. According to Curran ${ }^{[28]}$ "students need to learn the most effective ways to use these tools," as "technology is a tool used to improve nursing practice rather than an end in itself. Creating the most realistic environment for students eases their transition into the actual practice setting” (pp. 524-525). With so many different EHR systems in use nationally and internationally, and even within the same communities, nurses need to be facile at quickly learning new systems they encounter. As Fetter ${ }^{[29]}$ suggested, exposing students to multiple EHR formats and incorporating EHR documentation into classrooms and simulations will assist with enhancing nursing competencies and may even promote innovations.

Integrating an EHR into the curriculum enables students to apply classroom and textbook theory to practice. Students learn to recognize and pick out the relevant information from the electronic chart, setting aside the irrelevant and distracting data, just as they must do in actual clinical settings. The students are thus able to "practice at a higher level of critical thinking and clinical reasoning” ${ }^{[27]}$ (p. e-32). As Curran ${ }^{[28]}$ and Donahue and Thiede ${ }^{[27]}$ acknowledged, paper case studies used in classrooms often cannot provide the extent and scope of data afforded by cases available in educational EHRs. To that end, 
students in the current evaluation project felt the S/EHR was quite "complete", as reflected by the content analysis category, "Provided Extensive and In-depth Patient Data."

\section{Conclusions and limitations}

In conclusion, student perceptions of the S/EHR generally were positive, with the majority agreeing the system was realistic and easy to work with. The EHR component contributed to the realism of the simulation experiences. Students also perceived increased confidence and ability to safely provide patient care following practice with the S/EHR and felt it was important to have access to an EHR system. They also desired more simulations. For nursing programs exploring EHR options, considerations include ensuring the chosen system is consistent with program goals (e.g., to be used with clinical simulation); financially feasible for students and the nursing program; educationally sound (and not selected simply because it is inexpensive); realistic; easy to use, access, and understand; and enables student documentation that can readily be cleared or saved. A bonus is a system that provides instructors with the ability to modify patient data and create scenarios.

A limitation of this evaluation project pertained to the difficulty in distinguishing between the overall S/EHR and its EHR component. Attempting to evaluate the EHR separately from the S/EHR for some items may not have been appropriate since the S/EHR provided the patients that populated the EHR. Piloting the survey with more students could have afforded further feedback to assist with strengthening the evaluation tool. Additionally, other nursing programs needing to evaluate different EHR systems may want to include student groups throughout more of the decision making and evaluation processes, before even selecting an option to trial. Another limitation pertained to the very small number of students involved in this project. Furthermore, in part, because of the newness of this system to faculty and students, the S/EHR was not utilized to its full potential. For whichever EHR system attained by a nursing program, providing more orientation to faculty and students could facilitate better utilization and decrease frustration by both groups.

\section{Acknowledgement}

Project funded by a University of Wisconsin System Curricular Redesign grant submitted by the University of WisconsinMadison, University of Wisconsin-Eau Claire, University of Wisconsin-Green Bay, and the University of WisconsinOshkosh. Appreciation is extended to Dr. Patricia Brennan (Grant Project Director) and Ms. Pamela Scheibel (Grant Co-Project Director) at the University of Wisconsin-Madison School of Nursing, and to Ms. Nita Johnson, Skills and Simulation Laboratory Coordinator at the University of Wisconsin-Eau Claire.

\section{References}

[1] Mantas J, Ammenwerth E, Demiris G, Hasman A, Haux R, Hersh W, et al. Recommendations of the International Medical Informatics Association (IMIA) on education in biomedical and health informatics. Methods Inf Med. 2010 Jan 7; 49(2): 105-120. PMid:20054502 http://dx.doi.org/10.3414/ME5119

[2] Gray BH, Bowden T, Johansen I, Koch S. Electronic health records: an international perspective on "meaningful use". Commonwealth Fund. 2011 Nov; 28: 1-18.

[3] Centers for Medicare \& Medicaid Services. Medicare and Medicaid programs; electronic health record incentive program. Federal Register. 2010 July 28. Document No.: 2010-17207. Document Citation: 75 FR 44313. 276 p. Available from: https://federalregister.gov/a/2010-17207/.

[4] U.S. Department of Health and Human Services. Doctors and hospitals' use of health IT more than doubles since 2012 [Internet news release]. 2013 May 22 [cited 2014 May 26]. Available from http://www.hhs.gov/news/press/2013pres/05/20130522a.html.

[5] American Association of Colleges of Nursing. The essentials of doctoral education for advanced nursing practice. Washington, DC: American Association of Colleges of Nursing; 2006. 28 p.

[6] American Association of Colleges of Nursing. The essentials of baccalaureate education for professional nursing practice. Washington, DC: American Association of Colleges of Nursing; 2008. 61 p. 
[7] American Association of Colleges of Nursing. The essentials of master's education in nursing. Washington, DC: American Association of Colleges of Nursing; 2011. 64 p.

[8] National League for Nursing. Preparing the next generation of nurses to practice in a technology-rich environment: An informatics agenda. New York, NY: National League for Nursing; 2008. 6 p.

[9] Institute of Medicine. The future of nursing: Leading change, advancing health. Washington, DC: National Academic Press; 2011. $671 \mathrm{p}$.

[10] Lucas L. Partnering to enhance the nursing curriculum: electronic medical record accessibility. Clinical Simulation in Nursing. 2010; 6(3): e97-e102. http://dx.doi.org/10.1016/j.ecns.2009.07.006

[11] Morrow JB, Dobbie A. Using the electronic health record to enhance student learning. Fam Med. 2010 Jan; 42(1): 14-15. PMid:20063214

[12] Jeffries PR, Rogers K J. Theoretical framework for simulation design. In: Jeffries PR, editor. Simulation in nursing education: from conceptualization to evaluation. New York: National League for Nursing; 2007. p. 21-33.

[13] Bantz D, Dancer MM, Hodson-Carlton K, Van Hove S. A daylong clinical laboratory: from gaming to high-fidelity simulations. Nurse Educ. 2007 Nov/Dec; 32(6): 274-77. PMid:17998857 http://dx.doi.org/10.1097/01.NNE.0000299476.57185.f3

[14] Kennedy D, Pallikkathayil L, Warren JJ. Using a modified electronic health record to develop nursing process skills. J Nurs Educ. 2009 Feb; 48(2): 96-100. PMid:19260402 http://dx.doi.org/10.3928/01484834-20090201-07

[15] Connors H, Warren J, Weaver, C. HIT plants SEEDS in healthcare education. Nurs Admin Q. 2007 Apr/Jun; 31(2): $129-33$. PMid:17413506 http://dx.doi.org/10.1097/01.NAQ.0000264861.49217.f0

[16] Filer DA, Champlin B, Hunt R. Creating and implementing an unfolding multisetting simulation in a postbaccalaureate nursing program. Clinical Simulation in Nursing. 2012; 8(5): e181-e186. http://dx.doi.org/10.1016/j.ecns.2010.09.003

[17] Meyer MN, Connors H, Hou Q, Gajewski B. The effect of simulation on clinical performance: a junior nursing student clinical comparison study. Simulation in Healthcare. 2011 Oct; 6(5): 269-277. PMid:21785388 http://dx.doi.org/10.1097/SIH.0b013e318223a048

[18] Schaar GL, Ostendorf MJ, Kinner TJ. Simulation: linking quality and safety education for nurses competencies to the observer role. Clinical Simulation in Nursing. 2013 Sep; 9(9): e401-e404. http://dx.doi.org/10.1016/j.ecns.2012.07.209

[19] Tschetter L, Lubeck P, Fahrenwald N. Integrating QSEN and technology to address rural health care: initial outcomes. Clinical Simulation in Nursing. 2013 Oct; 9(10): e469-e475. http://dx.doi.org/10.1016/j.ecns.2012.09.005

[20] Gloe D. Selecting an academic electronic health record. Nurse Educ. 2010 Jul/Aug; 35(4): 156-161. PMid:20548183 http://dx.doi.org/10.1097/NNE.0b013e3181e337d3

[21] Nickitas DM, Nokes KM, Caroselli C, Mahon PY, Colucci DE, Lester RD. Increasing nursing student communication skills through electronic health record system documentation. CIN: Computers, Informatics, Nursing. 2010 Jan/Feb; 28(1): 7-11.

[22] Bowers AM, Kavanagh J, Gregorich T, Shumway J, Campbell Y, Stafford S. Student nurses and the electronic medical record: a partnership of academia and healthcare. CIN: Computers, Informatics, Nursing. 2011 Dec; 29(12): 692-97.

[23] Hanberg AD, Madden C. Tech-know-logy: using multimodal simulation strategies to bring data management and patient care technologies to life. Clinical Simulation in Nursing. 2011 Jul; 7(4): e133-e139. http://dx.doi.org/10.1016/j.ecns.2010.01.002

[24] Bearnson CS, Wiker KM. Human patient simulators: a new face in baccalaureate nursing education at Brigham Young University. J Nurs Educ. 2005 Sep; 44(9): 421-25. PMid:16220650

[25] Krippendorff K. Content analysis: an introduction to its methodology. Beverly Hills: Sage Publications; c1980. 191 p.

[26] Elo S, Kyngas H. The qualitative content analysis process. J Adv Nurs. 2008 Apr; 62(1): 107-115. PMid:18352969 http://dx.doi.org/10.1111/j.1365-2648.2007.04569.x

[27] Donahue B, Thiede K. Innovative strategies for nursing education: enhancing curriculum with the electronic health record. Clinical Simulation in Nursing. 2008; 4(1): e29-e34. http://dx.doi.org/10.1016/j.ecns.2009.05.053

[28] Curran CR. Faculty development initiatives for the integration of informatics competencies and point-of-care technologies in undergraduate education. Nurs Clin N Am. 2008; 43: 523-33. PMid:18940409 http://dx.doi.org/10.1016/j.cnur.2008.06.001

[29] Fetter MS. The electronic health record. Issues Ment Health Nurs. 2009 May; 30(5): 345-347. PMid:19437256 http://dx.doi.org/10.1080/01612840902754677 